\title{
O SERVIÇO DE PROTEÇÃO SOCIAL BÁSICA NO DOMICÍLIO PARA PESSOAS COM DEFICIÊNCIA E IDOSAS: ANÁLISES NO CENÁRIO NEOLIBERAL BRASILEIRO ${ }^{1}$
}

\author{
Nayara de Holanda Vieira - Universidade Federal do Piauí
}

\section{RESUMO}

O estudo objetiva efetivar uma revisão de literatura/bibliográfica acerca do cenário neoliberal brasileiro no que concerne a proteção social, a partir da garantia do serviço de proteção social básica no domicílio para pessoas com deficiência e idosas, através dos Centros de Referência de Assistência Social-CRAS. Trata-se de uma pesquisa teórica a partir de levantamento na base de dados no Scielo, Portal de Periódicos da CAPES/MEC, Portal Regional da BVS e Biblioteca Brasileira de Teses e Dissertações, além de seleção intencional de referências teóricas. A análise indica que a proteção social materializada por meio da implementação do serviço de proteção social básica no domicílio para pessoas com deficiência e idosas através dos CRAS, ainda é precária e aquém das demandas, estando na contramão do neoliberalismo.

Palavras-chave: Neoliberalismo; Proteção Social; Domicílio; Pessoas com Deficiência e Idosas

\section{ABSTRACT:}

The study aims to carry out a literature/bibliographic review about the Brazilian neoliberal scenario regarding social protection, from the guarantee of basic social protection service in the home for people with disabilities and elderly, through the Reference Centers of Social Assistance-CRAS. This is a theoretical research based on a survey in the Scielo database, Portal de Periódicos da CAPES/MEC, Portal Regional da BVS and Biblioteca Brasileira de teses e dissertações, as well as an intentional selection of theoretical references. The analysis indicates that the social protection materialized through the implementation of the basic social protection service in the home for people with disabilities and elderly through CRAS, is still precarious and below the demands, being the opposite of neoliberalismo.

Keywords: Neoliberalism; Social protection; Residence; Disabled and Elderly

\section{INTRODUÇÃO}

No contexto Neoliberal Brasileiro, os estudos acerca da garantia do Serviço de Proteção Social Básica no Domicílio para Pessoas com Deficiência e Idosas no tocante à materialização da proteção social, caracterizam-se como um campo científico ainda pouco explorado. Isso pode ser justificado pela parca produção de referenciais que abordem tal temática, que é possível observar

\footnotetext{
${ }^{1}$ Trabalho apresentado no Congresso Brasileiro Ciência e Sociedade (CBCS 2019), promovido pelo Centro Universitário Santo Agostinho, de 03 a 05 de outubro de 2019, em Teresina-PI.

${ }^{2}$ Assistente Social. Mestranda em Políticas Públicas (UFPI). Residente/Especialista em Saúde da Família e Comunidade pela Universidade Estadual do Piauí. nayarahol@gmail.com 
ANAIS CBCS 2019 | 3 a 5 de outubro de 2019 | Centro Universitário Santo Agostinho - Teresina - P

tendências indicativas a esse tipo de trabalho em âmbito domiciliar. São apresentados aqui, estudiosos que discutem a temática nas suas obras e que são abordagens referenciadas que servirão de embasamento para a inspiração e consolidação deste estudo.

Historicamente a tendência inicial do sistema de proteção social no Brasil remete aos anos 1930, período em que o país assume o modelo urbano-industrial e abandona a base econômica prioritariamente agroexportadora. Tem-se a ascensão da burguesia industrial emergindo a classe trabalhadora urbana, duas forças antagônicas que fazem existir conflitos sociais e demandam intervenção direta do poder público, que o faz mediante a sistematização de um sistema de proteção social de natureza meritocrática e particularista, voltada para os trabalhadores assalariados com carteira assinada.

O arranjo vivenciado nesse contexto, é apresentado e denominado por Santos (1987, apud TEIXEIRA 2007) de cidadania regulada, baseada na estratificação ocupacional e na renda adquirida no nível dessa estrutura, o que reforçava as desigualdades sociais no país, baseada em uma conotação corporativista.

Essas características que marcaram o início do sistema protetivo brasileiro, não foi diferente com o regime militar, especialmente nas décadas de 1960 e 1970. Prevaleceu um reformismo centralizador, burocrático e tecnocrático, gerido por um Estado autoritário e fortemente atrelado ao setor privado (COBO, 2012).

Diante de um sistema protetivo mais unificado e coeso, que ocorre no final dos anos 80 , havendo ampliação dos direitos sociais, que deveriam ser garantidos através da Constituição Federal de 1988, não obstante, é vivenciada uma crise financeira e administrativa acentuada naquele período, reflexo da crise mundial do capitalismo, e passa-se a implementar as políticas neoliberais.

No final da década de 1980, eclodem uma conjuntura de movimentos sociais pela redemocratização do país, pela liberdade política e pela instauração de um sistema protetivo democrático e universalista. A mobilização social culminou na promulgação da Constituição Federal de 1988, que apresenta uma nova configuração formal no âmbito das políticas sociais, distinta da 
ANAIS CBCS 2019 | 3 a 5 de outubro de 2019 | Centro Universitário Santo Agostinho - Teresina - PI

herança passada, uma vez que coloca a política de proteção social como direito social e de responsabilidade prioritária do Estado, ou seja, como dever público.

Contudo, a carta magna e as legislações subsequentes do sistema de proteção social do país, na década de 1990, ao invés de presenciar a consolidação da proposta de universalização dos direitos sociais ancorados no sistema brasileiro de proteção social, assiste à sua tentativa de desmonte pela adoção da lógica neoliberal mediante os interesses do capitalismo globalizado e competitivo, que se propõe a reduzir a responsabilidade pública na condução das políticas sociais (GOMES, 2015).

Em tal contexto, o neoliberalismo é tomado como ideário que preconiza, conforme Laurell (2002), a diminuição dos gastos sociais, a redução dos serviços sociais públicos, com eliminação de programas e minimização de benefícios, a entronização do mercado como mecanismo dos recursos econômicos e da satisfação das necessidades dos indivíduos, a competição e o individualismo e as novas relações de produção, que desregulamenta e flexibiliza as relações trabalhistas, rechaça os direitos sociais e responsabiliza a sociedade pelo aferimento desses direitos, sendo este o cenário característico do início dos anos 90.

A conjuntura atual, na turbulência social, um movimento paradoxal se instaura: se, de um lado, cabe à família o papel de centralidade nas políticas sociais, inclusive na política pública de Assistência Social; por outro, o mesmo segmento sofre os efeitos perversos (DAGNINO, 2004) com a desresponsabilização crescente do Estado nas políticas sociais, agudizando especialmente os contextos familiares mais vulneráveis (GOMES, 2015).

Desta feita, torna-se necessário analisar o papel das políticas públicas na garantia de direitos, especialmente das pessoas com deficiência e idosas, o acesso e a prevenção de agravos de vulnerabilidades que possam fragilizar e romper os vínculos familiares e sociais desses segmentos populacionais no cenário Neoliberal. Estes, que na sua grande maioria, por apresentarem vulnerabilidades sociais, inclusive associadas a barreiras atitudinais e/ou sociogeográficas, à dependência de cuidados de terceiros ou à mobilidade limitada, que dificultam ou impedem a 
ANAIS CBCS 2019 | 3 a 5 de outubro de 2019 | Centro Universitário Santo Agostinho - Teresina - PI

adesão, o acesso ou a participação regular nos serviços, especificamente os ofertados nos espaços/unidades do Sistema Único de Assistência Social-SUAS e no território, de maneira geral.

Além disso, é preciso levar em conta que o suporte do serviço às dinâmicas no ambiente do domicílio, envolvendo familiares, vizinhos e a comunidade, pode ser considerado o atendimento mais adequado para atender às necessidades específicas dos usuários, tendo em vista o acesso a direitos, o fortalecimento da autonomia e das relações de cuidado e convívio familiar e social. (BRASIL, 2012).

Este estudo tem como objetivo refletir sobre a garantia do serviço de proteção social básica no domicílio para pessoas com deficiência e idosas, através dos Centros de Referência de Assistência Social-CRAS, no cenário neoliberal brasileiro, baseado nas mudanças em curso da política pública de Assistência Social, resultantes das situações de vulnerabilidade e/ou risco social vivenciadas por este público, a partir da reflexão do papel das políticas públicas, da família e da comunidade.

A Política de Proteção Social no Brasil se consubstancia no formato de Seguridade Social a partir da Constituição Federal de 1988 que a compreende como um conjunto integrado de ações de iniciativa dos Poderes Públicos e da sociedade, destinadas a assegurar os direitos relativos à Saúde, à Previdência e à Assistência Social (BRASIL, 1988).

A política pública de Assistência Social que volta à cena por intermédio dos artigos 203 e 204 da Constituição, que a interpreta como matéria política de responsabilidade do Estado e direito permanente de todo cidadão, sendo deste modo ratificada no artigo primeiro da Lei Orgânica da Assistência Social -LOAS, $n^{\circ} 8.742$ de 7 de dezembro de 1993 e regulamentada pela Lei no 12.435 de 06 de julho 2011, que discorre acerca da organização da assistência social no Brasil

No cenário neoliberal, é possível destacar o direcionamento do atendimento de tal política no que se refere a situação de vulnerabilidade social, considerada enquanto modo de compreender a realidade dessas famílias, resultantes de processos de precarização das condições de existência que se acentuam com as políticas neoliberais. A vulnerabilidade é identificável quando há falhas nas condições de acesso a bens materiais e bens de serviços, que possam suprir aquilo que pode tornar o indivíduo vulnerável (AYRES et al., 2006). 
ANAIS CBCS 2019 | 3 a 5 de outubro de 2019 | Centro Universitário Santo Agostinho - Teresina - PI

Nessa ótica, a exclusão e a inacessibilidade desencadeiam riscos que levam a população a se expor em eminentes situações de "sofrimento", que a vulnerabilidade, num âmbito social, deve estudar, ajudar a entender e a responder (MILANESE; SOUSA, 2015).

As ofertas da Proteção Social Básica são organizadas por meio do Centro de Referência da Assistência Social-CRAS, que é uma unidade pública estatal descentralizada, de base territorial e gestão municipal e do Distrito Federal (MDS, 2012). Dentre um dos serviços que devem ser ofertados e garantidos é o Serviço de Proteção Social Básica no Domicílio para Pessoas com Deficiência e Idosas, com a finalidade de garantir o acesso a direitos e a prevenção de agravos de vulnerabilidades que possam fragilizar e romper os vínculos familiares e sociais dos usuários (BRASIL, 2009).

O cuidado e o campo da assistência domiciliar conquistaram destaque especial com o avanço da Estratégia de Saúde da Família - ESF, no ano de 2002 e foi acrescentada à Lei Orgânica de Saúde no 8080/90 um capítulo referente ao atendimento domiciliar prevendo a intervenção e acompanhamento de equipes multiprofissionais (BRASIL, 2002; BRASIL, 2012).

$O$ atendimento domiciliar não se restringe somente aos serviços de saúde. Com o intuito de potencializar a execução da Política Nacional de Assistência Social através do acompanhamento familiar, em 2009, com a Resolução № 109 que caracteriza a Tipificação dos Serviços Socioassistenciais em todos os municípios brasileiros, esse documento dispõe sobre o trabalho social com as famílias para prevenir situações de risco social, bem como o trabalho "realizado em grupos, organizado a partir de percursos, de modo a garantir aquisições progressivas aos seus usuários, de acordo com seu ciclo de vida" (BRASIL, 2009, p. 09).

O Serviço de Proteção Social Básica no domicílio para pessoas com deficiência e idosas é definido pela Tipificação (BRASIL, 2009) como um serviço que tem por "finalidade a prevenção de agravos que possam provocar o rompimento de vínculos familiares e sociais dos usuários. Visa à garantia de direitos, o desenvolvimento de mecanismos para a inclusão social" (p. 15).

No ano de 2016, foi lançado pelo Ministério do Desenvolvimento Social, o Caderno de Orientações Técnicas sobre o Serviço de Proteção Social Básica no Domicílio para pessoas com 
ANAIS CBCS 2019 | 3 a 5 de outubro de 2019 | Centro Universitário Santo Agostinho - Teresina - P

deficiência e idosas com o objetivo de cada vez mais aproximar o Estado do cidadão, em uma atitude de reconhecimento do domicílio como um espaço privilegiado de proteção e cuidado e, sobretudo, de acesso a direitos (BRASIL, 2016).

Tal dispositivo vem normatizar o serviço que já é previsto no âmbito da assistência social e de todos as legislações e cadernos de orientações técnicas que vem corroborar com a implementação de fato para o funcionamento do serviço no âmbito domiciliar. Vale ressaltar que apesar de normatizado esse serviço não é implementado em muitos municípios brasileiros.

\section{METODOLOGIA}

O trabalho fundamentou-se no levantamento do 'estado da arte' ou 'estado do conhecimento', que, segundo Morosini e Fernandes (2014, p. 155), corresponde a "identificação, registro e categorização que levem à reflexão e síntese sobre a produção cientifica de uma determinada área, em um determinado espaço de tempo, congregando periódicos, teses, dissertações e livros sobre uma temática específica" na perspectiva de informar os aspectos e dimensões que mais tiveram destaque, remetidos ao contexto do serviço de proteção social básica no domicílio para pessoas com deficiência e idosas, a partir da política pública de Assistência Social.

Para identificar sobre a garantia do serviço de proteção social básica no domicílio para pessoas com deficiência e idosas, a partir da política pública de Assistência Social, foi realizada uma revisão de literatura com seleção intencional da referência teórica.

Ao analisar com mais detalhes a discussão, diante de tais referenciais, a autora realizou ainda um levantamento bibliográfico nas bases de dados eletrônica da Scielo, Portal de Periódicos da CAPES/MEC, Portal Regional da BVS e Biblioteca Brasileira de Teses e Dissertações com os seguintes descritores: "neoliberalismo" e "proteção social" e "domicílio" e "pessoas com deficiência e idosas". 
ANAIS CBCS 2019 | 3 a 5 de outubro de 2019 | Centro Universitário Santo Agostinho - Teresina - P

Considerou-se como critérios de inclusão: publicações em português e completas que fossem compreendidas no período mais recente e que abordassem sobre o atendimento domiciliar garantido a pessoas com deficiência e idosas e como critérios de exclusão: os textos que fossem repetidos. Os descritores acima destacados resultaram em 15 textos. No entanto, considerando a aplicação dos métodos de inclusão e de exclusão foram contemplados 8 artigos para imersão das discussões em torno do objeto. Ressalta-se que a análise de conteúdo, na sua vertente temática, foi empregada para tratamento do material acessado (BARDIN, 2006).

Discutir sobre a garantia do serviço de proteção social básica no domicílio para pessoas com deficiência e idosa, no cenário neoliberal brasileiro, permite ampliar e fortalecer as políticas públicas nesse contexto, dentre estas, especificamente, a política pública de assistência social e com foco para este público, com vistas à garantia da proteção social através da concretização do serviço de proteção social básica no domicílio, tendo o serviço como espaço de produção e interação com os profissionais, as pessoas com deficiência, a família e a comunidade.

\section{RESULTADOS E DISCUSSÕES}

Diante do cenário neoliberal, em um contexto de desmonte de direitos sociais, é possível identificar, a partir da visualização do Plano Municipal de Assistência Social de 2018 a 2021, que não há previsão de investimentos nesse serviço, que sequer aparece entre os serviços que serão alvo de expansão ou implementação na atual conjuntura. Os relatórios de gestão anuais também não trazem nenhuma informação sobre sua implementação. Essa realidade é visível nos vários municípios brasileiros.

O questionário do Censo Suas antes de 2018 sequer incluía esse serviço com dados e levantamento de sua execução nos municípios, pelos parcos investimentos financeiros, humanos e intelectuais no e sobre o serviço. Há ainda, uma dificuldade de entender teoricamente como seria a contribuição da assistência social no trabalho em domicílio, que tipos de cuidados prestaria. Além 


\section{CONGQEESSOCIENCIAESOCIEDADE

ANAIS CBCS 2019 | 3 a 5 de outubro de 2019 | Centro Universitário Santo Agostinho - Teresina - PI

disso, as pequenas equipes e sem infraestrutura adequada para o deslocamento se somam aos problemas teóricos e financeiros.

Além disso, em cenário regressivo das políticas sociais se espera que o trabalho no domicílio se restrinja ao das famílias, geralmente realizado por mulheres. Cabendo as equipes do CRAS a orientação e algum tipo de acompanhamento. A literatura apesar de abordar o serviço é menos de análises de sua implementação, pela escassez dessa na maioria dos municípios brasileiros, e mais pelas potencialidades dos serviços se fossem implementados na lógica do acesso e materialização de direitos, quer individuais quer familiares.

De tal forma, em consonância com o panorama brasileiro, em que é identificado ainda escassa a produção de referenciais que abordem tal temática, desse contexto ainda pouco explorado, além de trazer à tona a discussão da implementação, existência e garantia de tais serviços que caracterizem o significado e a materialização de Proteção Social. Essa experiência é visualizada a partir de pesquisas e levantamentos dos documentos dos Censo SUAS, visto que os dados dos censos anteriores aos de 2018 não previa elementos que comprovassem a implementação do serviço a partir dos CRAS.

Contudo, já foi identificado no questionário do Censo SUAS do CRAS para ser preenchido referente aos dados do ano de 2018, no bloco cinco deste, destaques sobre as informações, desde a quantificação dos indivíduos atendidos, se idosos, se pessoas com deficiência e as respectivas quantidades, o tipo de ações e atividades que são realizadas no âmbito do domicílio, entre outras informações relevantes sobre o serviço de proteção social básica no domicílio para pessoas com deficiência e idosas.

\section{CONSIDERAÇÕES FINAIS}

A Política Nacional de Assistência Social (PNAS, 2004) consolida o reconhecimento da Assistência Social como direito do cidadão e responsabilidade do Estado que tem se fortalecido na 
ANAIS CBCS 2019 | 3 a 5 de outubro de 2019 | Centro Universitário Santo Agostinho - Teresina - P

articulação e no esteio das lutas da sociedade brasileira pelos direitos de crianças, adolescentes, juventude, pessoas idosas, pessoas com deficiência, mulheres, pessoas em situação de rua, entre outros segmentos e assim a família.

Demarca a especificidade da proteção social da Assistência Social e a direção das suas ofertas, no campo das políticas sociais, garantindo por meio dos seus serviços, benefícios, programas e projetos as seguintes seguranças: segurança de sobrevivência-renda e autonomia, segurança de acolhida e segurança de convívio ou vivência familiar e comunitária e social (BRASIL, 2005).

Nessa direção, a PNAS, ao prever o público demandante das suas ações e benefícios, inclui os cidadãos e grupos que se encontram em situações de vulnerabilidade e riscos, entre os quais: famílias e indivíduos com perda ou fragilidade de vínculos de afetividade, pertencimento e sociabilidade; ciclos de vida; identidades estigmatizadas em termos étnico raciais, culturais, de gênero e em desvantagem pessoal resultante de deficiência.

Com base nas legislações, as ofertas da Proteção Social Básica são organizadas por meio do Centro de Referência da Assistência Social - CRAS, com funções de gestão territorial da rede socioassistencial local e a execução do Serviço de Proteção e Atendimento Integral a Família - PAIF, o Serviço de Convivência e Fortalecimento de Vínculos - SCFV e o Serviço de Proteção Social Básica no Domicílio para Pessoas com Deficiência e Idosas, estes metodologicamente apresentado pela Tipificação Nacional dos Serviços Socioassistenciais, a partir da Resolução no 109 de 11 de novembro de 2009.

Na contemporaneidade, a ênfase na garantia de direitos das pessoas idosas e pessoas com deficiência, no que tange, ao atendimento voltado para estes no âmbito domiciliar, emerge da legitimação de conquistas através dos dois públicos, desde a Política Nacional do Idoso em 1994, assim como da Lei Brasileira de Inclusão da Pessoa com Deficiência que cria o Estatuto da Pessoa com Deficiência em 2015, entre outras legislações que contribuem para a ampliação da proteção e do cuidado. 
ANAIS CBCS 2019 | 3 a 5 de outubro de 2019 | Centro Universitário Santo Agostinho - Teresina - P

Para efeito do trabalho social do serviço no domicílio, faz-se importante considerar também o domicílio territorial (bairro, comunidade, região) onde a pessoa mora, partindo da forma como é organizada sua dinâmica cotidiana e acesso às políticas públicas, contribuindo para que famílias, cidadãos e territórios ampliem suas capacidades protetivas em relação às pessoas idosas e às pessoas com deficiência.

É percebido, que a garantia de tal serviço para pessoas com deficiência e idosas, encontrase em processo inicial de execução e ainda de forma considerável limitada, em algumas realidades. Assim, seus limites, potencialidades e desafios ainda são pouco abordados na literatura. Constatase que ainda é muito falha a atuação do Estado por meio dos serviços ofertados, frente aos novos papéis direcionados as famílias e a comunidade, que por muitas vezes estão envoltos por outras fragilidades resultantes de diversas situações de vulnerabilidade e/ou risco social.

Esses aspectos estão intimamente influenciados pelas transformações advindas dos pressupostos neoliberais que têm se firmado no recuo da atuação do Estado na intervenção social e trazem alguns desafios nessa arena, como por exemplo, o de assegurar espaços de divisão de cuidados para amenizar os impactos das sobrecargas e o preparo de profissionais para atuar com as pessoas com deficiência, idosos e os familiares, contribuindo significativamente para o aumento das desigualdades e o acirramento da pobreza, o que reflete diretamente na família.

\section{REFERÊNCIAS}

AYRES, J. R. et. al. Você aprende. A gente ensina? Interrogando relações entre educação e saúde desde a perspectiva da vulnerabilidade. Cadernos de Saúde Pública. Rio de Janeiro, v. 22, n. 6, p. 1.335-1.342, jun. 2006

BARDIN, L. Análise de conteúdo (L. de A. Rego; A. Pinheiro, Trads.). Lisboa: Edições 70. 2006. (Obra original publicada em 1977).

BRASIL. Constituição da República Federativa do Brasil de 1988. 7ạ ed. São Paulo: Editora Revista dos Tribunais, 2001. 


\section{CONGEESSO CIENCIAESOCIEDADE Inovação, Diversidadie e Sustentahilitidade}

ANAIS CBCS 2019 | 3 a 5 de outubro de 2019 | Centro Universitário Santo Agostinho - Teresina - PI

. Lei Orgânica da Assistência Social (LOAS). Lei n 8.742, de 07 de dezembro de 1993.

. Ministério do Desenvolvimento Social e Combate à Fome. Política Nacional de Assistência Social (PNAS). Brasília: MDS\SNAS, 2004. . Ministério do Desenvolvimento Social e Combate

à Fome. Norma Operacional Básica da Assistência Social (NOB\SUAS). Brasília: MDS\SNAS, 2005.

. Ministério da Saúde. Norma Operacional Básica da Saúde (NOB/SUS). Brasília, 2006.

- Conselho Nacional de Assistência Social. Tipificação Nacional de Serviços

Socioassistenciais. Resolução no 109, de 11 de novembro de 2009. Brasília, 2009.

- Ministério do Desenvolvimento Social e Combate à Fome. Secretaria Nacional de Assistência Social. Orientações Técnicas Sobre o PAIF: O Serviço de Proteção e Atendimento Integral à Família - PAIF segundo a Tipificação Nacional dos Serviços Socioassistenciais - Vol 1-Brasília, 2012.

. Conselho Nacional de Assistência Social. Resolução no 33, de 12 de dezembro de 2012. Norma Operacional Básica do Sistema Único de Assistência Social - NOB/SUAS, 2012.

- Ministério do Desenvolvimento Social e Combate à Fome. Secretaria Nacional de Assistência Social. Orientações Técnicas Sobre o PAIF: Trabalho Social com Famílias do Serviço de Proteção e Atendimento Integral à Família - PAIF - Vol 2-Brasília, 2012.

. Secretaria Nacional de Direitos Humanos da Presidência da República. Cartilha do Censo 2010, Pessoas com Deficiência. Brasília: 2012.

. Lei no 8.842 , de 4 de janeiro de 1994. Dispõe sobre a política nacional do idoso, cria o Conselho Nacional do Idoso e dá outras providências. Brasília: MPAS, 1994. 


\section{CONGEESSO CIENCIAESOCIEDADE Inovação, Diversidadie e Sustentahilitidade}

ANAIS CBCS 2019 | 3 a 5 de outubro de 2019 | Centro Universitário Santo Agostinho - Teresina - PI

Proteção Social Básica no Domicílio para Pessoas com Deficiência e Idosas. Brasília, Ministério do Desenvolvimento Social e Combate à Fome, Brasília. 2017.

COBO, B. Políticas focalizadas de transferência de renda: contextos e desafios. São Paulo: Cortez, 2012.

DAGNINO, E. Construção democrática, neoliberalismo e participação: os dilemas da confluência perversa. Revista Política e Sociedade, no 5, outubro de 2004.

GOMES T. B. A família em situação de vulnerabilidade social no contexto hodierno da desinstitucionalização psiquiátrica. Dissertação (Mestrado em Políticas Públicas e Sociedade). Universidade Federal do Ceará, 2015.

LAURELL, A. C. Avançando em direção ao passado: a política social do neoliberalismo. In: LAURELL, A. C (Org.). Estado e políticas sociais no neoliberalismo. 3. ed. São Paulo: Cortez, 2002.

MILANESE, E.; SOUSA, P. C. Vulnerabilidade social: uma reflexão sobre o conceito. In: ROSA, L. C. S. et. al (Orgs.). CRR Articulando a RAPS: a construção de novas práticas e saberes no Piauí, Brasília, Verbis Editora, 2015, p. 431- 445.

MOROSINI, M. C; FERNANDES, C. M. B. Estado do Conhecimento: conceitos, finalidades e interlocuções. Revista: Educação Por Escrito, Porto Alegre, v. 5, n. 2, p. 154-164, jul.-dez. 2014.

TEIXEIRA, S. M. Reforma da previdência social no Brasil: modernização ou desmonte da seguridade social? Serviço Social e Contemporaneidade: Revista do Departamento de Serviço Social/ Universidade Federal do Piauí, ano V, n. 5, Teresina, EDUFPI, 2007. 